\title{
Tergitol Konsantrasyonun Ni-B/hBN Kompozit Kaplamaların Elektrodepolanması Üzerine Etkisi
}

\author{
Ali TOZAR ${ }^{1^{*}}$ \\ ${ }^{1}$ Hatay Mustafa Kemal Üniversitesi, Fen-Edebiyat Fakültesi, Fizik Bölümü, Hatay. \\ *Sorumlu Yazar e-posta: tozarali@gmail.com. \\ ORCID ID: https://orcid.org/0000-0003-3039-1834
}

Geliş Tarihi: 09.07.2019 Kabul Tarihi: 18.02.2020

\begin{tabular}{|c|c|}
\hline & ذ́z \\
\hline & Bu çalışmada endüstriyel olarak sıklıkla kullanılan 304L kalite çelik altlıklar üzerine, üstün katı yağlayıcılık \\
\hline Anahtar kelimele & ve mekanik mukavemet özellikleri gösteren hegzagonal bor nitrür (hBN) nano partikülleriyle \\
\hline $\begin{array}{l}\text { Elektrodepolama; } \\
\qquad \mathrm{Ni-B}\end{array}$ & $\begin{array}{l}\text { desteklenmiş nikel-bor (Ni-B) alaşım matrisli kompozit kaplamalar galvanostatik elektrodepolama } \\
\text { yoluyla kaplanmıstır. Calısmada Tergitol }{ }^{\mathrm{TM}} \text { yüzey aktif madde (sürfaktan) olarak kullanılmıs ve bu yüzey }\end{array}$ \\
\hline Mikrosertlik; & aktif maddenin depolama süspansiyonundaki konsantrasyonunun kaplamaların yapısal, morfolojik, \\
\hline $\begin{array}{l}\text { ¿zey Aktif Madde; } \\
\text { Korozyon }\end{array}$ & $\begin{array}{l}\text { mikrosertlik, ve korozyon koruma özellikleri üzerine etkisi sırasıyla XRD, FE-SEM, Vickers mikrosertlik, } \\
\text { potansiyodinamik polarizasyon ve elektrokimyasal empedans spektroskopisi kullanılarak incelenmiştir. }\end{array}$ \\
\hline & Sonuç olarak, Tergitol'ün metal matrisli kompozit kaplamaların elektrodepolanması için etkili bir yüzey \\
\hline & aktif madde olarak kullanılabileceği sonucuna varılmıştır. \\
\hline
\end{tabular}

\section{Effect of the Tergitol Concentration on the Electrodepositon of Ni- $\mathrm{B} / \mathrm{hBN}$ composite Coatings}

\begin{tabular}{cl} 
Keywords & Abstract \\
\cline { 2 - 3 } Electrodeposition; & In this study, hexagonal boron nitride (hBN) nanoparticles which has superior solid lubrication and \\
Ni-B; & mechanical strength properties reinforced nickel-boron (Ni-B) alloy matrix composite coatings were \\
Microhardness; & fabricated by galvanostatic electrodeposition on $304 \mathrm{~L}$ grade steel widely used in the industry. In the \\
Surfactant; & study, Tergitol TM was used as a surfactant. The effect of the surfactant concentration on the structural, \\
Corrosion & morphological, microhardness, and corrosion protection properties of the coatings was investigated \\
& using XRD, FE-SEM, Vickers microhardness, potentiodynamic polarization, and electrochemical \\
& impedance spectroscopy, respectively. It was concluded that Tergitol ${ }^{\mathrm{TM}}$ can be used as an effective \\
& surfactant for electrodeposition of metal matrix composite coatings.
\end{tabular}

(C) Afyon Kocatepe Üniversitesi

\section{Giriş}

Endüstri ve mühendislik alanında kullanılan malzemeler ekstrem koşullara maruz kalır ve bu nedenle hızla korozyona ve aşınmaya maruz kalırlar. Korozyon ve aşınmaya bağlı bozulmalar her yıl dünya çapında milyarlarca dolarlık zarara mal olmaktadır. Ekstrem koşullara maruz kalan malzeme yüzeyinin Nikel (Ni) ve Nikel alaşımları ile kaplanması, yüksek mekanik dayanıklılık, iyi korozyon direnci ve uygun maliyetleri nedeniyle etkili bir yöntem olarak kullanılagelmiştir. Çok yönlülükleri nedeniyle elektrodepolama ve akımsız (electroless) depolama, endüstriyel olarak en çok tercih edilen tekniklerdir. Son yıllarda, nikel-bor ( $\mathrm{Ni}$ B) alaşım kaplamaların önemi, havacılık, kimya ve otomotiv sektörlerinin yüksek korozyon, mekanik ve tribolojik dayanım talepleri doğrultusunda giderek artmaktadır (Offoiach et al. 2019).

Her ne kadar akımsız depola tekniği ile ilgili iyileştirilme çalışmaları olsa da yüksek sıcaklık ve $\mathrm{pH}$ gereksinimi ve bu parametrelerin çok sıkı şekilde stabilizasyonuna olan ihtiyaç, bu yöntemin endüstriyel kullanımını sınırlamaktadır. Bu bağlamda, Ni-B alaşım kaplamaların elektrodepolama tekniğiyle üretilmesi endüstriyel 
kullanım için daha uygundur (Mehr et al. 2019). Bu nedenle araştırmacılar, son yıllarda Ni-B alaşımlı kaplamaların elektrodepolanması konusuna yoğunlaşmışlardır (Kwon et al. 2017, Matsui et al. 2018, Ogihara et al. 2011). Özellikle, elektrodepolanmış Ni-B alaşım kaplamaların korozyonun dirençleri, mekanik ve tribolojik performanslarının artırııması üzerinde birçok çalışma gerçekleştirilmiştir. Ni-B kaplamaların mekanik özelliklerinin nispeten artmasına rağmen, ısıl işlem sonucu oluşan mikro çatlaklar nedeniyle korozyon koruma özellikleri düşebilmektedir (Wang et al. 2012). Isıl işlem sonrası oluşan olumsuzlukları ortadan kaldırmak için, seramikle güçlendirilmiş $\mathrm{Ni}$ matrisli kompozit kaplamaların elektrodepolanması, son çalışmaların üzerinde durduğu etkili bir stratejidir (Li et al. 2019, Mehr et al. 2019).

Bu çalışmalar, pH (Zhu et al. 2019), akım yoğunluğu (Zhang, R.Y., Li, et al. 2019), depolama sıcaklığı (Kumaraguru Mohan 2018) ve katkı tipi (Mirzamohammadi et al. 2017) ve konsantrasyonu (Zhang, Y.H., Feng, et al. 2019) gibi elektrodepolama işlemini etkileyen birçok parametre üzerine yoğunlaşmıştır. Özellikle, katkı maddesinin tipi ve konsantrasyonu $\mathrm{Ni}$ matris kompozitlerin elektrodepolanması üzerinde büyük etki göstermektedir (Afroukhteh et al. 2012, Gyawali et al. 2014). Katkı maddesi olarak farklı yüzey aktif maddeler (katyonik veya noniyonik) yalnızca $\mathrm{Ni}$ matrisli kompozitlerinin elektrodepolanması için değil, aynı zamanda diğer metal matrisli kompozitlerin elektrodepolanması için kullanılmıştır. Sürfaktanlar (surfactant), yüzey morfolojisinin modifikasyonu ile kompozit malzemenin fiziksel özelliklerini değiştirebilmektedir (Maharana Basu 2018). Olumlu etkileri hem altlık yüzeyine adsorpsiyon hem de seramik partikülleri stabilize etme ve metal matrisin içerisine iyi dağıtmasından kaynaklanmaktadır. Özellikle, noniyonik sürfaktanlar seramik parçacıklarının topaklaşmasının engellenmesi nedeniyle film üzerindeki takviye malzemesi içeriğini kontrollü bir şekilde arttırmaktadır (Maharana et al. 2018). Noniyonik bir sürfaktan olan Tergitol $^{\mathrm{TM}}$, metallerin, alaşımların veya nikel, nikel alaşımları ve kompozitler elektrodepolanması üzerindeki etkisi henüz hiç araştırılmamıştır. Bu çalışmada Tergitol konsantrasyonunun $\mathrm{Ni}-\mathrm{B} / \mathrm{hBN}$ kompozit kaplamaların elektrodepolanması üzerindeki etkisi yapısal, mekanik ve korozyon önleme özellikleri açısından incelenmiştir. Bu çalışma Tergitol'ün metal matrisli kompozit kaplamaların elektrodepolanmasında yüzey aktif madde (sürfaktan) olarak kullanılmasına yönelik ilk çalışmadır.

\section{Materyal ve Metot}

Temel elektrodepolama süspansiyonunun bileşimi ve elektrodepolama parametreleri Tablo 1'de verilmiştir. Bütün kimyasallar Sigma-Aldrich firmasından temin edilmiştir. Depolama süspansiyonları deiyonize su kullanılarak hazırlanmıştır. Çalışmada $100 \mathrm{~nm}$ ortalama tanecik boyutlu hBN tozları kullanılmıştır. Bu çalışmada, birçok türü bulunan Tergitol 'ün sıvı formu olan 15S-7 tipi kullanılmıştır. Tergitol konsantrasyonunun kompozit kaplamanın fiziksel özellikleri üzerindeki etkisin araştırmak için $0,0.01,0.02,0.03,0.04$ $\mathrm{ml} / \mathrm{L}^{\prime} l i k 5$ farklı Tergitol süspansiyonundan elektrodepolama işlemleri gerçekleştirilmiştir.

Çizelge 1. Temel elektrodepolama süspansiyonunun bileşimi ve elektrodepolama parametreleri.

\begin{tabular}{lr}
\hline Kimyasal & \\
\hline $\mathrm{NiSO}_{4} \cdot 6 \mathrm{H}_{2} \mathrm{O}$ & $250 \mathrm{~g} \cdot \mathrm{L}^{-1}$ \\
$\mathrm{NiCl}_{2} \cdot 6 \mathrm{H}_{2} \mathrm{O}$ & $55 \mathrm{~g} \cdot \mathrm{L}^{-1}$ \\
$\mathrm{H}_{3} \mathrm{BO}_{3}$ & $35 \mathrm{~g} \cdot \mathrm{L}^{-1}$ \\
$\mathrm{TMAB}$ & $6 \mathrm{~g} \cdot \mathrm{L}^{-1}$ \\
$\mathrm{hBN}$ & $12 \mathrm{~g} \cdot \mathrm{L}^{-1}$ \\
Tertigol (15-S-7)) & \\
& $0,0.01,0.02,0.03,0.04 \mathrm{ml} / \mathrm{L}$ \\
\hline Elektrodepolama Prametreleri & \\
\hline Sıcaklık & $43{ }^{\circ} \mathrm{C}$ \\
pH & 4 \\
Akım Yoğunluğu & $50 \mathrm{~mA} \cdot \mathrm{cm}{ }^{-2}$ \\
Depolama Zamanı & $60 \mathrm{~min}$. \\
Karıştırma Hızı & $250 \mathrm{rpm}$ \\
\hline
\end{tabular}

Tüm elektrokimyasal analiz ve sentez çalışmaları 250 $\mathrm{ml}$ hacimli cam beher kullanılarak gerçekleştirilmiştir. Standart 3 elektrotlu elektrokimyasal hücrede, referans elektrot olarak doymuş kalomel (SCE), karşıt elektrot olarak platin tel ve altlık olarak sanayi tipi 304 L kalite çelik kullanılmıştır. Elektrodepolama işlemi öncesinde yeni hazırlanmış süspansiyonlara 30 dakika süre ile $300 \mathrm{~W}$ güçte ultrasonik karıştırma uygulanmıştır (Unal ve Karahan 2018).

Kaplamaların kristalografi incelemeleri için, X-Işını difraksiyonu (XRD) deneyleri $40 \mathrm{kV}$ ve $30 \mathrm{~mA}$ ile oluşturulan $\mathrm{CuK}_{\alpha}$ radyasyonu kullanan Rigaku X-Ray 
difraktometresi ile gerçekleştirildi. Tarama hızı $3.0 \%$ dak ve yatay geliş açısı (grazing incidence) $5^{\circ}$ idi. Kaplamaların yüzey morfolojisi incelemeleri için, $\mathrm{X}$ ışını spektrometresi (EDS) aparatına sahip Apreo $S$ marka alan emisyon-taramalı elektron mikroskobu (FE-SEM) kullanılmıştır.

Tercihli kristal yönelimlerinin sayısal bir kıyaslaması için XRD verilerinden ve 01-079-6756, 01-079-2916 00-004-0850 no'lu ICDD (uluslararası kristal kırınım veri merkezi) kartları kullanılarak bağıl doku katsayıları (relative texture coefficient, RTC) aşağıdaki denklem 1'den hesaplanmıştır (Gu et al. 2018);

$$
\% R T C(h k l)=\frac{T C(h k l)}{\sum T C(h k l)}
$$

Burada TC(hkl), (hkl) yöneliminin ve $\sum T C(h k l)$ bütün doku katsayılarının toplamıdır. TC(hkl) ise aşağıdaki denklem 2'den hesaplanabilir (Yousif et al. 2017);

$T C(h k l)=\frac{\mathrm{I}(h k l)}{\sum \mathrm{I}(h k l)} x \frac{\sum \mathrm{I}_{0}(h k l)}{\mathrm{I}_{0}(h k l)}$

Burada I(hkl), (hkl) yönelimine ait pikin şiddeti, $\sum \mathrm{I}(h k l)$ ise bütün yönelimlere ait piklerin şiddetleri toplamıdır. Ayrıca $\mathrm{I}_{0}(\mathrm{hkl})$ referans kartta ilgili pikin şiddetidir.

Mikromekanik karakterizasyon deneyleri için klasik Vickers mikrosertlik cihazı kullanılmıştır. Daha iyi bir istatistik dağılım sağlamak için 10 mikroindent kaplamanın farklı bölgelerine $1 \mathrm{kgf}$ ile uygulanmıştır. Kaplamaların korozyon koruma performanslarının değerlendirilmesi için Tafel ekstrapolasyon ve elektrokimyasal empedans spektroskopisi (EIS) deneyleri, ağırlıkça \% 3.5'luk $\mathrm{NaCl}$ çözeltisi ile gerçekleştirilmiştir. Tafel deneyleri için tarama hızı 1 $\mathrm{mV} / \mathrm{s}$ ve potansiyel aralığı açık devre potansiyeline karşı-0.250 ile $1 \mathrm{~V}$ olarak gerçekleştirildi. Elektrokimyasal empedans spektroskopisi deneyleri açık devre potansiyelinde, $10 \mathrm{mV}$ genlikli bir AC sinyal $100 \mathrm{kHz}$ ila $10 \mathrm{mHz}$ frekansları taranarak gerçekleştirildi.

\section{Bulgular ve Tartışma}

Şekil 1a ve b, sırasıyla elektrodepolanmış Ni-B/hBN kompozit kaplamaların XRD spektrumlarını ve bağıl doku katsayı (relative texture coefficient, RTC) grafiklerini göstermektedir. Şekil 1'e göre, ana kristalleşme, saf Ni'e (110), (200) ve (220) ait olan üç ana düzleminde gerçekleşmiştir. Diğer taraftan, Ni-B alaşımına karşılık gelen ancak Ni pikleriyle örtüşen
(130) ve (221) düzlemleri ICDD referans kartlarında tanımlanabilir. XRD desenlerinde Tergitol konsantrasyonunun artmasıyla birlikte tanecik küçülmesine karşılık gelen pik genişlemesi görülebilir. Bu, Tergitol moleküllerini Nikelin aktif çekirdekleşme bölgelerini kapatarak büyük çekirdekler oluşturmasına engel olmasına bağlanılabilir (Zhou et al. 2018). Ayrıca, hBN (002) pikinin yoğunluğu, artan Tergitol konsantrasyonuyla artmaktadır, bu da hBN partiküllerinin matristeki aynı yönde yerleşimlerini gösterir. RTC grafiğinden görülebileceği gibi, Ni-B matrisinin ana kristalleşme paterni önemli ölçüde değişmemiştir. Bununla birlikte, Tergitol'ün artan konsantrasyonları ile (220) düzleminin RTC'si düşerken, (111) düzleminin RTC'si ilk önce yükselmiş ve sonra düşmüştür.

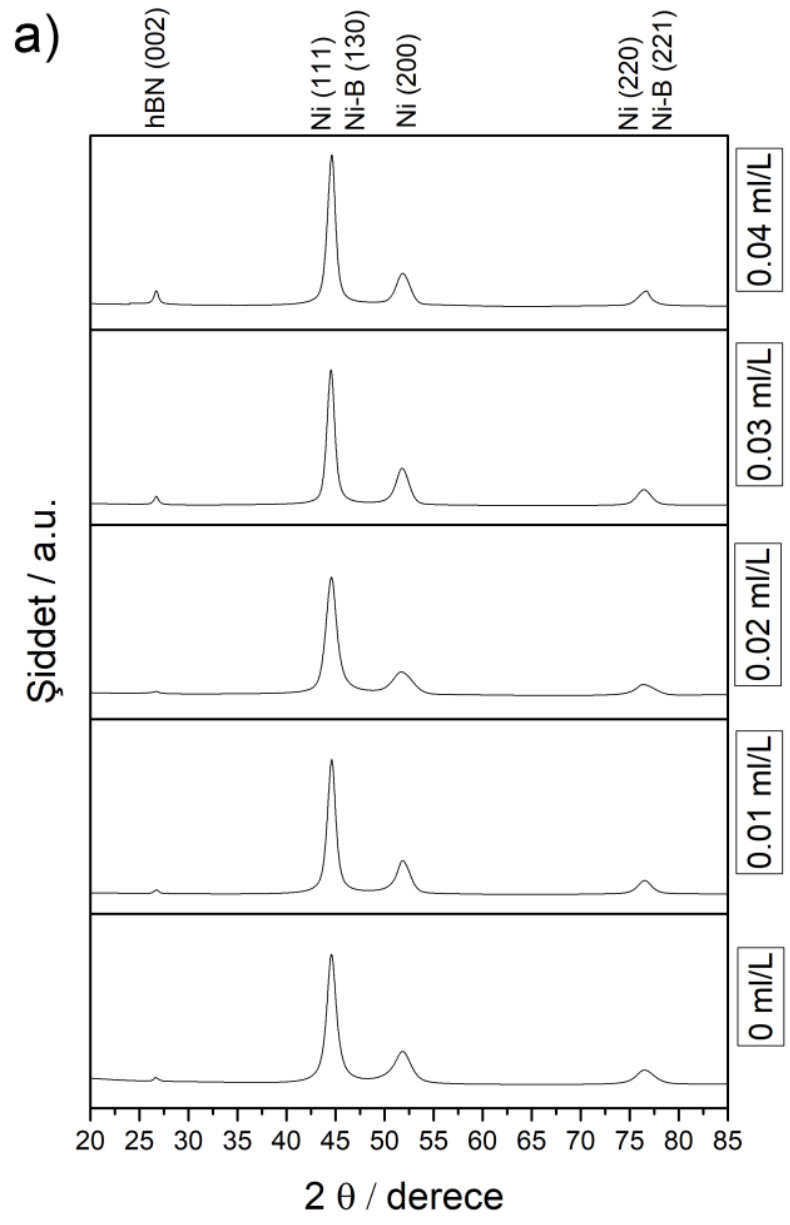




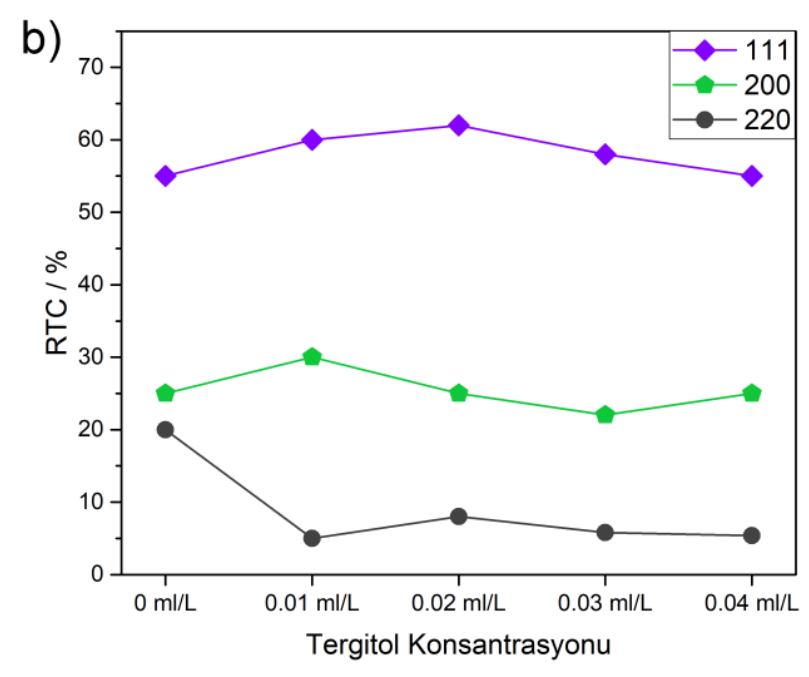

Şekil 1. (a) Kaplamalara ait XRD desenleri, (b) temel kristalizasyon düzlemlerine ait RTC (bağıl doku katsayısı) grafiği.
Şekil 2, kaplamaların SEM ve optik mikroskop görüntülerini göstermektedir. Şekle göre, Tergitol'ün elektrodepolama süspansiyonuna katılmasıyla önemli bir morfoloji değişikliği baş göstermiştir. Benzer bir morfoloji değişim gözlemi, Mardani ve Ershadifar tarafından gerçekleştirilmiştir (Mardani et al. 2018). Bu değişiklik, elektrodepolama süspansiyonunun yapısının viskozite, zeta potansiyeli ve elektrokimyasal bakımından değişmesi nedeniyle tane küçülmesine bağlanabilir. Tergitol'ün, depolama süspansiyonunun zeta potansiyelini değiştirdiği ve sonuç olarak, altlık yüzeyine taşınması olası askıya alınmış hBN parçacıklarının sayısını arttırdığı varsayılabilir. Tablo 2 'de verilen, kaplama içindeki hBN parçacıklarının hacimsel fraksyonu bu görüşü desteklemektedir.
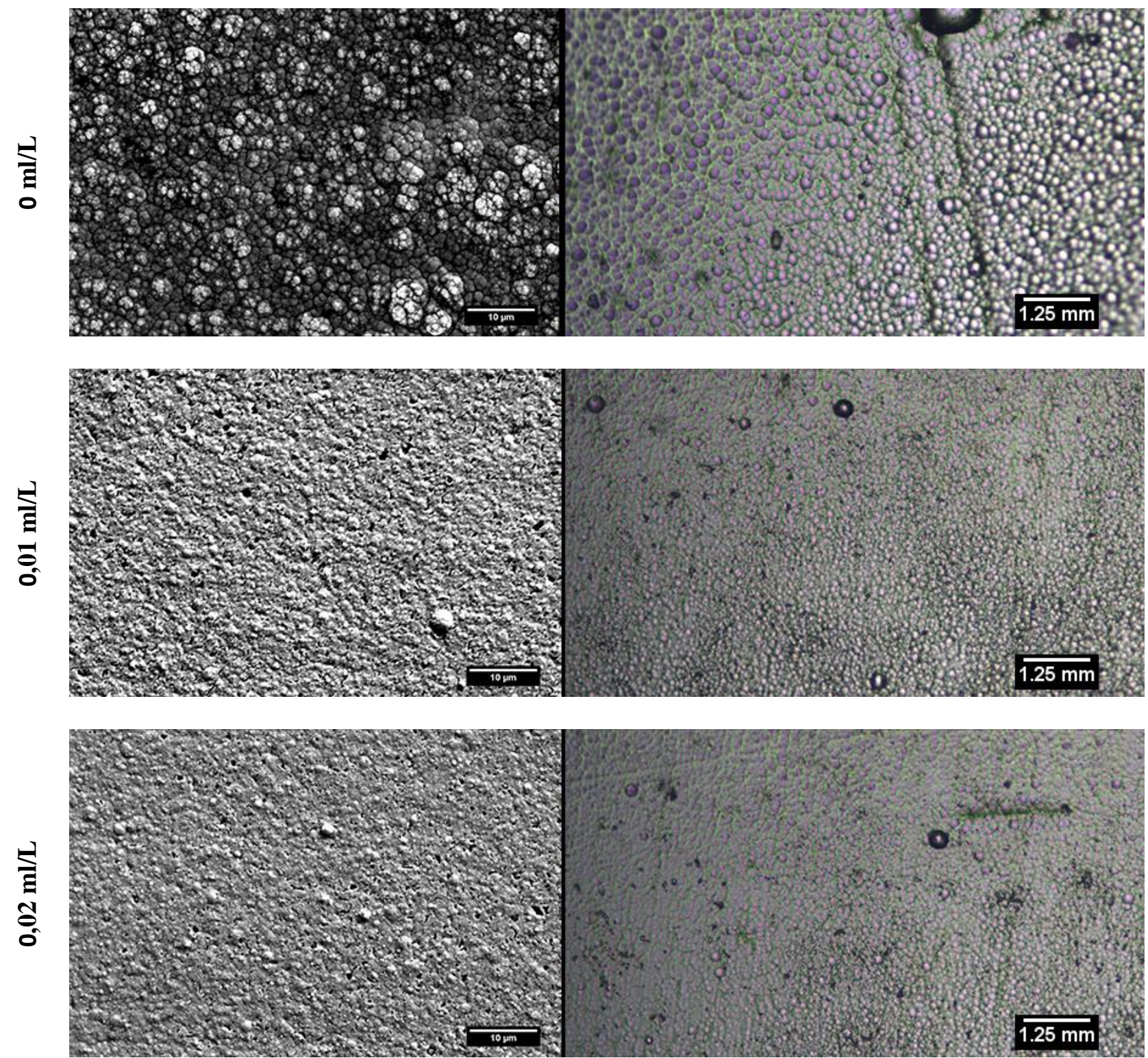

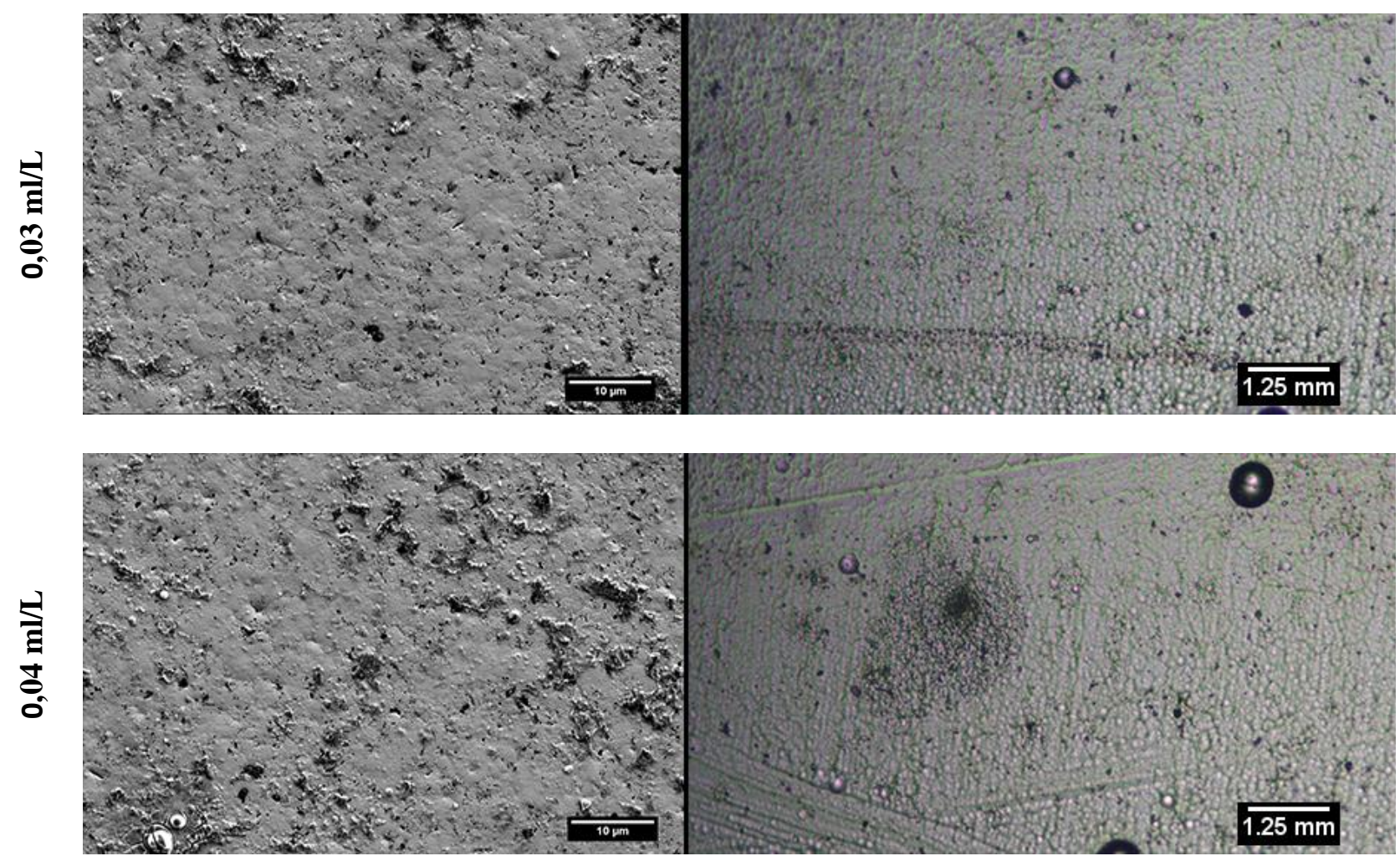

Şekil 2. Kaplamalara ait, FE-SEM görüntüleri (solda), optik mikroskop görüntüleri (sağda).

Şekil 3, kompozit kaplamaların Vickers mikrosertlik değerleri ve istatistiksel olarak elde edilen standart sapmaları göstermektedir. Her numuneye 10 mikro indent uygulanarak sonuçlar elde edilmiştir. Şekle göre, artan Tergitol konsantrasyonları ile kaplamaların $\mathrm{HV}_{1}$ sertlik değerleri düzenli bir şekilde artmıştır. Kaplamadaki hBN miktarının artması nedeniyle, Vickers sertliği, $0.04 \mathrm{ml} / \mathrm{L}$ ile üretilen kaplama için $712 \mathrm{HV}_{1}$ 'e yükselmiştir. Bu sertleşme hem destek malzemenin hacim fraksiyonunun artmasına hem de matris boyunca uygun dağılmasına bağlanılabilir. Ancak hBN parçacıkları yüzey boyunca farklı dağılıma sahip olabileceğinden dolayı bu kaplamaya ait standart sapma değeri diğerlerine göre daha yüksektir.

Çizelge 2. Tergitol konsantrasyonuyla hBN'ün hacim fraksoyunun, kaplamanın mikrosertliğnin, korozyon potansiyeli ve hızının değişimi.

\begin{tabular}{ccccc}
\hline $\begin{array}{c}\text { Tergitol } \\
\text { Konsantra } \\
\text { syonu } \\
(\mathrm{ml} / \mathrm{L})\end{array}$ & $\begin{array}{c}\text { hBN } \\
\text { Parçacıklarının }\end{array}$ & $\begin{array}{c}\text { Mikro } \\
\text { Sertlik }\end{array}$ & $\begin{array}{c}\text { Korozyon } \\
\text { Potansiyeli } \\
\left(\mathrm{E}_{\text {corr }}\right)\end{array}$ & $\begin{array}{c}\text { Korozy } \\
\text { on Hızı }\end{array}$ \\
\hline 0 & 4.25 & 365 & -0.545 & 3.924 \\
$(\mathrm{~V})$ & $(\mathrm{HV})$ & -0.521 & 3.236 \\
0.1 & 6.43 & 448 & -0.486 & 2.001 \\
0.2 & 10.54 & 502 & -0.468 & 0.501 \\
0.3 & 14.91 & 652 & -0.420 & 0.376 \\
0.4 & 18.34 & 712 & & \\
\hline
\end{tabular}

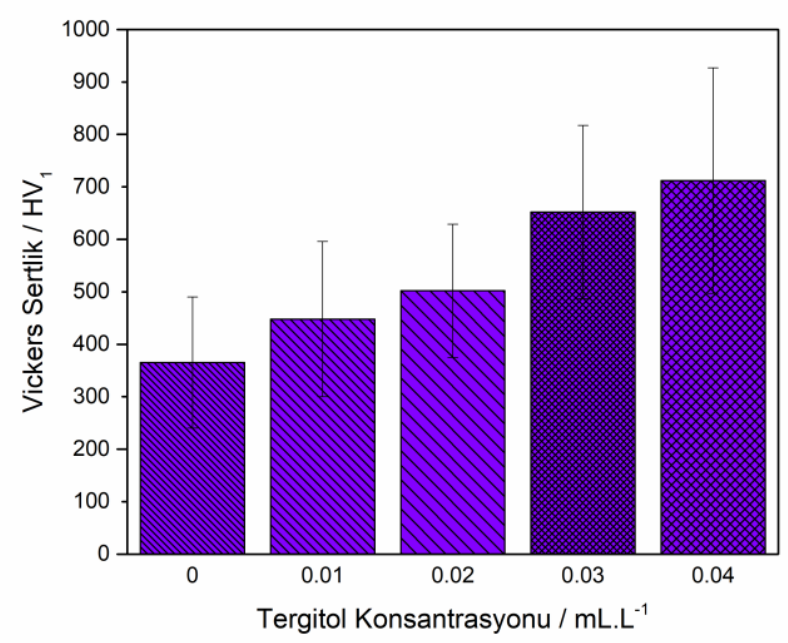

Şekil 3. Artan Tergitol konsantrasyonuyla kaplamaların mikrosertlik değerlerinin değişimi.

Şekil 4 0,04 ml/L Tertigol konsantrasyonunda elektrodepolanmış kompozit kaplamaya ait bir Vickers mikroindentinin optik resmini göstermektedir. Şekilden görüleceği gibi, mikroindent izinin her iki dikey doğrultusu hemen hemen aynı boyutlardadır. Bu boyutlar için $\mathrm{HV}_{1}$ değeri 692 olarak hesaplanmıştır. İz etrafında plastik akış (plastic flow), yığılma (pile-up) veya çatlak (fracture) gibi olumsuzluklar görülmemiştir. 


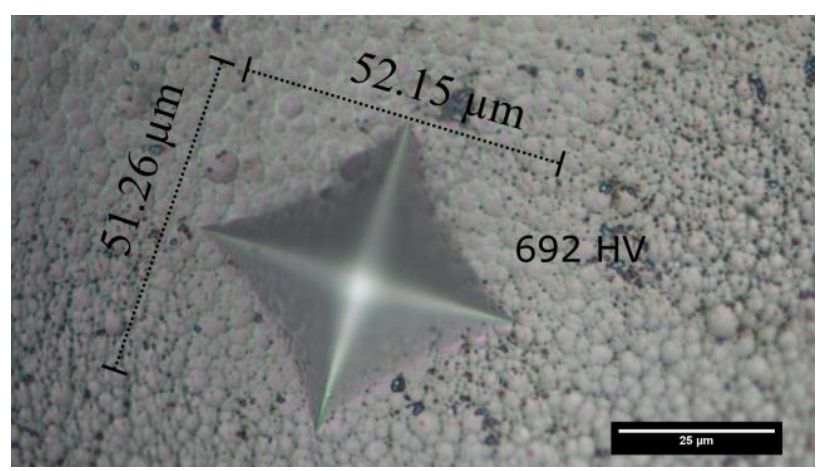

Şekil 4. 0,04 $\mathrm{ml} / \mathrm{L}$ Tergitol konsantrasyonunda elektrodepolanan kaplamaya uygulanan bir indentin optik mikroskop görüntüsü.

Şekil 5a ve b, sırasıyla elektrodepolanmış Ni-B/hBN kaplamaların ve kaplamasız çeliğin potansiyodinamik polarizasyon (Tafel) eğrilerini ve empedans modül değerlerini göstermektedir. Polarizasyon eğrilerine göre, kompozit kaplamalı çeliklerin korozyon potansiyeli ( $\left.\mathrm{E}_{\text {corr }}\right)$ kaplamasız çeliğe göre daha anodik tarafa kaymıştır. Bu, kaplamaların korozif ortamın altlık yüzeyine ulaşmasını engelleyerek bariyerleme özelliği ile çeliği koruduğunun bir göstergesidir. $-442 \mathrm{mV} \mathrm{E}_{\text {corr }}$ değeri ile, $0.04 \mathrm{ml} / \mathrm{L}$ Tergitol konsantrasyonu kullanılarak üretilen kompozit kaplama, en anodik korozyon potansiyeli değerine sahiptir. Benzer şekilde, $0.04 \mathrm{ml} / \mathrm{L}$ Tergitol konsantrasyonu kullanılarak üretilen kaplama, tüm kaplamalar arasında en düşük anodik çözünme akımı değerine sahiptir. Öte yandan, polarizasyon eğrilerinin anodik taraflarında, artan Tergitol konsantrasyonları ile anodik çözünme akımında kademeli bir azalma görülebilmektedir. Bu, altlık kaplama sisteminin anodik olarak polarize olduğu bölgede düşük korozyon oranlarının bir göstergesidir.

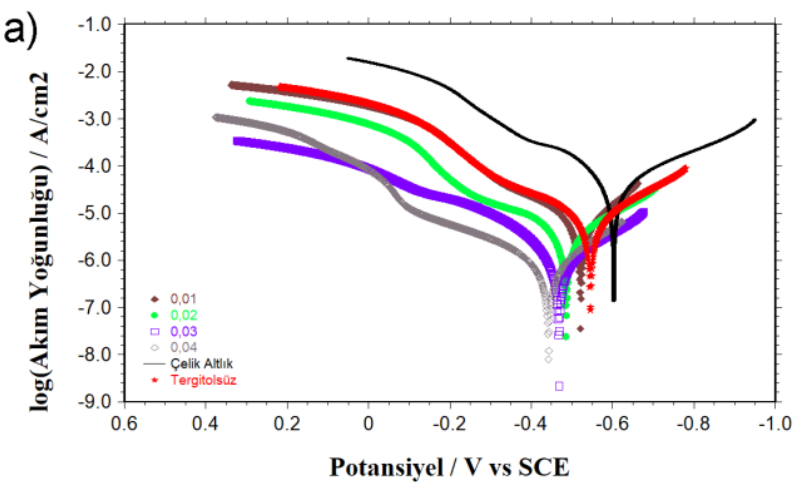

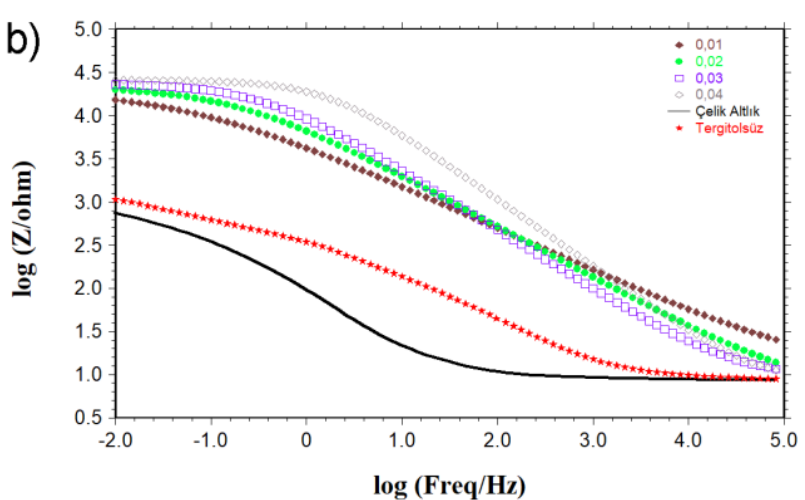

Şekil 5. Kütlece $\% 3,5^{\prime}$ lik NaCl çözeltisinde kaydedilen, (a) Tafel eğrileri, (b) AC empedans modülüs grafikelri.

Elektrodepolanmış $\mathrm{Ni}-\mathrm{B} / \mathrm{hBN}$ kaplamaların ve kaplaması çeliklerin empedans modülü grafiklerinden görülebileceği gibi, potansiyodinamik polarizasyon eğrileri ile iyi bir uyum görülebilir. Kaplamalar, tüm frekans bölgeleri boyunca çeliğe ve Tergitol'süz olarak üretilen kaplamaya göre çok daha yüksek empedans değerlerine sahiptir. Daha iyi bariyer özelliklerinin bir göstergesi olarak, düşük frekans bölgesinde, artan Tergitol konsantrasyonları ile kaplamaların empedans modülü değerleri artmıştır. $0.04 \mathrm{ml} / \mathrm{L}$ konsantrasyonu kullanılarak üretilen kaplamanın, matris boyunca iyi dağılmış destek parçacıklı yapısı ve kaplamanın yüzeyi iyi kapatması nedeniyle tüm kaplamalar arasında en iyi korozyon koruma performansını gösterdiği kolayca söylenebilir. Bu kaplamanın üstün korozyon koruma özellikleri tablo 2'de verilen korozyon hızlarından da görülebilmektedir. Bu durum üstün yüzey kapatma özelliği sağlayan yüksek adsorpsiyon entropisine bağlanılabilir (Nam et al. 2014).

\section{Tartışma ve Sonuç}

Bu çalışmada, Ni-B/hBN kompozit kaplamalar, çelik levhalar üzerinde galvanostatik olarak elektrodepolanmıştır. Tergitol konsantrasyonunun kaplamaların yapısal, mekanik ve korozyon koruma performansları üzerine etkisi incelenmiştir. Bulgularımıza göre, Tergitol kaplamaların yüzey morfolojisi üzerinde dikkate değer bir etkiye sahiptir. Öte yandan, Tergitol kaplamaların sadece mekanik özellikleri değil aynı zamanda korozyon koruma özelliklerini de olumlu yönde etkilemiştir. Bu olumlu etki, Tergitol'ün süspansiyonun kolloidal süreçlerine etkisiyle süspansiyonun stabilitesini arttırması ve üstün ıslatıcı (wetting) özellikleri sayesinde kaplama yüzeyini geliştirmesine bağlanılabilir. Tergitol'ün artan konsantrasyonları, 
hBN partiküllerinin hacim fraksiyonunu arttırmıştır ve kaplamalardaki dağılımlarını iyileştirmiştir. Sonuç olarak, Tergitol'ün metal matriks kompozit kaplamaların elektrodepolanması için etkili bir yüzey aktif madde olarak kullanılabileceği sonucuna varılmıştır.

\section{Teşekkür}

Mustafa Kemal Üniversitesi Bilimsel Araştırma

Projeleri Destekleme Birimi'ne bu çalışmaya mali destek sağladıkları için teşekkür ederiz (Proje No: 19 M 020).

\section{Kaynaklar}

Afroukhteh, S., Dehghanian, C. and Emamy, M. (2012). Corrosion behavior of Ni-P/nano-TiC composite coating prepared in electroless baths containing different types of surfactant. Progress in Natural Science: Materials International, 22(5), 480-487.

Gu, W., Liu, C., Tang, J., Liu, R., Yang, H. and Hu, J. (2018). Improving zinc electrodeposition in ammoniacal electrolytes with the saturated dissolved methyltrioctylammonium chloride. Hydrometallurgy, 175, 43-51.

Gyawali, G., Hamal, K., Joshi, B., Rajbhandari, A. and Wohn Lee, S. (2014). Microstructural and electrochemical analysis of $\mathrm{Ni}-\mathrm{SiC}$ composite coatings prepared in presence of additives. Materials Letters, 126, 228-231.

Kumaraguru, S. and Mohan, S. (2018). Study of Ni-Bi2O3$\mathrm{CeO} 2$ composite coatings: Hierarchical microstructure and augmented microhardness for surface engineering application. Surface \& Coatings Technology, 349, 567-575.

Kwon, H. B., Kim, K., Ahn, H. R. and Kim, Y. J. (2017). Electrodeposition and Characterization of Nanocrystalline Ni-B with Low Boron Content for MEMS Applications. Sensors and Materials, 29(3), 225-234.

Li, B. S., Huan, Y. X., Luo, H. and Zhang, W. W. (2019). Electrodeposition and properties of $\mathrm{Ni}-\mathrm{B} / \mathrm{SiC}$ nanocomposite coatings. Surface Engineering, 35(2), 110-120.

Maharana, H. S. and Basu, A. (2018). Effects of Different Surfactants on Structural, Tribological and Electrical Properties of Pulsed ElectroCodeposited $\mathrm{Cu}$-ZrO2 Composite Coatings. Journal of Materials Engineering and Performance, 27(4), 1854-1865.
Mardani, R., Asrar, A. and Ershadifar, H. (2018). The effect of surfactant on the structure, composition and magnetic properties of electrodeposited CoNiFe /Cu microwire. Materials Chemistry and Physics, 211, 160-167.

Matsui, I., Omura, N., Yamamoto, T. and Takigawa, Y. (2018). Electrodeposition with intermittent addition of trimethylamine borane to produce ductile bulk nanocrystalline Ni-B alloys. Surface \& Coatings Technology, 337, 411-417.

Mehr, M. S., Akbari, A. and Damerchi, E. (2019). Electrodeposited $\mathrm{Ni}-\mathrm{B} / \mathrm{SiC}$ micro- and nanocomposite coatings: A comparative study. Journal of Alloys and Compounds, 782, 477-487.

Mirzamohammadi, S., Khorsand, H. and Aliofkhazraei, M. (2017). Effect of different organic solvents on electrodeposition and wear behavior of $\mathrm{Ni}$ alumina nanocomposite coatings. Surface \& Coatings Technology, 313, 202-213.

Nam, D.-H., Kim, T.-H., Hong, K.-S. and Kwon, H.-S. (2014). Template-Free Electrochemical Synthesis of $\mathrm{Sn}$ Nanofibers as High-Performance Anode Materials for Na-Ion Batteries. ACS Nano, 8(11), 11824-11835.

Offoiach, R., Lekka, M., Lanzutti, A., Martinez-Nogues, V., Vega, J. M., Garcia-Lecina, E. and Fedrizzi, L. (2019). Tribocorrosion study of $\mathrm{Ni} / \mathrm{B}$ electrodeposits with low B content. Surface \& Coatings Technology, 369, 1-15.

Ogihara, H., Miyamoto, K., Udagawa, K. and Saji, T. (2011). Electrodeposition of Super Hard Ni$\mathrm{B} /$ Diamond Composite Coatings. Chemistry Letters, 40(10), 1072-1073.

Unal, E. and Karahan, I. H. (2018). Effects of ultrasonic agitation prior to deposition and additives in the bath on electrodeposited $\mathrm{Ni}-\mathrm{B} / \mathrm{hBN}$ composite coatings. Journal of Alloys and Compounds, 763, 329-341.

Wang, Z. C., Yu, L., Jia, F. and Song, G. L. (2012). Effect of Additives and Heat Treatment on the Formation and Performance of Electroless Nickel-Boron Plating on AZ91D Mg Alloy. Journal of the Electrochemical Society, 159(7), D406-D412.

Yousif, A., Kumar, V., Jafer, R. M. and Swart, H. C. (2017). The effect of different annealing temperatures on the structure and luminescence properties of Y2O3:Bi3+ thin film fabricated by RF magnetron sputtering. Applied Surface Science, 424, 407411. 
Zhang, R. Y., Li, Z. L., Yu, X. and Cui, G. (2019). Characterisation and properties of Ni-W-Y2O3$\mathrm{ZrO} 2$ nanocomposite coating. Surface Engineering, 35(7), 578-587.

Zhang, Y. H., Feng, L. and Qiu, W. (2019). Effects of glycine on mechanical properties and microstructure of diamond-reinforced Ni nanocomposite coatings. Journal of Materials Science, 54(13), 9507-9522.

Zhou, X., Wang, Y., Liang, Z. and Jin, H. (2018). Electrochemical Deposition and Nucleation/Growth Mechanism of Ni-Co- $\mathrm{Y}_{2} \mathrm{O}_{3}$ Multiple Coatings. Materials (Basel, Switzerland), 11(7), 1124.

Zhu, H. M., Geng, S. J., Chen, G. and Wang, F. H. (2019). $\mathrm{Ni}-\mathrm{Mn} 3 \mathrm{O} 4$ Composite Coating by Electrophoresis/Electrodeposition for Metallic Interconnects Applications. Journal of the Electrochemical Society, 166(6), F423-F430. 